\title{
Biological evaluation of a mechanical ventilator that operates by controlling an automated manual resuscitator. A descriptive study in swine
}

\section{Maryanne Melanie Gonzales Carazas}

PUCP: Pontificia Universidad Catolica del Peru

\section{Cesar Miguel Gavidia}

Universidad Nacional Mayor de San Marcos

\section{Roberto Davila Fernandez}

Universidad Nacional Mayor de San Marcos

Juan Alberto Vargas Zuñiga

Centro de Urgencias Veterinarias (CUVET)

Alberto Crespo Paiva

Instituto Veterinario de Oftalmologia (IVO)

William Bocanegra

Universidad Nacional Mayor de San Marcos

Joan Calderon

Universidad Nacional Mayor de San Marcos

Evelyn Sanchez

Universidad Nacional Mayor de San Marcos

\section{Rosa Perales}

Universidad Nacional Mayor de San Marcos

\section{Brandon Zeña}

Instituto Veterinario de Oftalmologia (IVO)

Juan Fernando Calcina Isique

Universidad Nacional Mayor de San Marcos

Jaime Reategui

Amazon.com Dedc LLC Breinigsville 650 Boulder

Benjamin Castañeda Aphan

PUCP: Pontificia Universidad Catolica del Peru

Fanny Lys Casado ( $\nabla$ fanny.casado@pucp.edu.pe )

Pontificia Universidad Católica del Perú: Pontificia Universidad Catolica del Peru https://orcid.org/0000-0002-8791-626X 
Keywords: mechanical ventilation, biological evaluation, preclinical trial, swine, blood biochemistry

Posted Date: May 6th, 2021

DOI: https://doi.org/10.21203/rs.3.rs-473026/v1

License: (c) (1) This work is licensed under a Creative Commons Attribution 4.0 International License. Read Full License 


\section{Abstract \\ Background}

The Covid-19 outbreak challenged health systems around the world to design and implement costeffective devices to complement mechanical ventilators that can be produced locally. Masi works as a mechanical ventilator to bring life-support by automating a resucitation bag to closely control ventilatory parameters.

\section{Methods}

This pre-clinical trial was designed to study the physiological responses of healthy swine maintained under volume- or pressure-controlled mechanical ventilation. Thus, physiological parameters were measured in eight sedated animals $\left(t_{0}\right)$, prior to inducing deep anesthesia, as well as during the next six hours of mechanical ventilation with Masi $\left(\mathrm{t}_{1-7}{ }^{-7}\right)$. Hemodynamic conditions were monitored periodically using a gas analyzer machine (i.e. $\mathrm{BEecf}_{1} \mathrm{HCO}_{3}, \mathrm{SaO}_{2}$, lactate, $\mathrm{pH}, \mathrm{PaO}_{2}, \mathrm{PaCO}_{2}$ ) and a capnometer (i.e. $\mathrm{ETCO}_{2}$ ). Electrocardiogram, echocardiography and lung ultrasonography were performed to detect in vivo alterations in these vital organs and pathological findings from necropsy are reported.

\section{Results}

The mechanical ventilator properly controlled physiological levels of blood biochemistry such as oxygenation parameters $\left(\mathrm{PaO}_{2}, \mathrm{PaCO}_{2}, \mathrm{SaO}_{2}, \mathrm{ETCO}_{2}\right)$, acid-base equilibrium $\left(\mathrm{pH}, \mathrm{HCO}_{3}{ }^{-}, \mathrm{BEecf}\right)$, and perfusion of tissues (lactate levels). In addition, histopathological analysis showed no evidence of acute tissue damage in lung, heart, liver, kidney, or brain. Moreover, all animals were able to breathe spontaneously after undergoing mechanical ventilation controlled by Masi device. The results demonstrate that Masi mechanical ventilator allows the regulation of body gas exchange and maintain the physiological parameters in the normal range for swine.

\section{Conclusions}

These preclinical data, added to the appropriate performance of Masi in engineering laboratory tests, support the biological safety of the medical device to move forward to further evaluation in clinical studies.

\section{Background}

COVID-19 is a disease caused by the coronavirus SARS-CoV-2, initially detected in China, rapidly expanded worldwide from January to March $2020[1,2]$. Few days after the detection of the first case of 
COVID-19 in Peru (March 6th, 2020) [3], a status of National Public Health Emergency was declared [4] based on the lack of preparedness which included medical devices used at Intensive Care Units (ICU) such as mechanical ventilators. To alleviate this need, a multidisciplinary professional group designed and developed Masi (meaning friend or partner in the Quechua language), a mechanical ventilator for the COVID-19 emergency as the first mechanical ventilator to be mass-produced in Peru [5] .

Masi is an automated ventilator that works in three different operating modes based on the mandatory ventilation controlled by either volume (PC-CMV) or pressure (VC-CMV), and support ventilation under positive pressure (PSV). Additionally, the device senses and regulates inspiration and expiration parameters, respiratory rate, oxygen flow, among others. Masi was designed to meet the requirements established by the Pan American Health Organization/ World Health Organization (PAHO/WHO) [6] and the Medicines and Healthcare products Regulatory Agency (MHRA, United Kingdom) [7] for mechanical ventilators to manage COVID-19 atypical pneumonia in health services.

The operating mechanism of Masi is similar to other ventilator devices used in the clinic during the health emergency internationally (i.e., Spiro Wave [USA, www.ventilatorresponse.com], Respira [Spain, www.respiradevice.com], OxyGEN [Italy, www.oxygen.protofy.xyz]). Although these emergency ventilators may not offer all of the features of a state-of-the technology commercial hospital ventilator to attend all respiratory emergencies, there are some patients who may benefit from these less complex mechanical ventilator systems. This includes the milder and initial cases of COVID-related pneumonia, i.e. support patients for some hours or even a day, and assist low body weight individuals with respiratory failure, i.e. women and adolescents [8, 9]. A mechanical ventilator to operate a resuscitation bag while sensing oxygen flow, it is a simpler alternative to current commercial devices for debilitated health systems due to the COVID-19 outbreak.

However, these medical use devices need to validate their mechanical functions using a test lung simulator in a metrology laboratory, as well as their effects biological models. In this regard, swine models for respiratory translational studies have been validated by similarities found from diverse clinical points of view, i.e anatomical, histological, and microbiological proximities $[10,11]$. Therefore, pigs are a relevant model for preclinical studies of mechanical ventilators [12, 13].

Thus, performance and electrical safety of Masi were validated using international standards and approved technical tests at the engineering laboratory level [5]. Consequently, this paper describes the methodology to use a mechanical ventilator (Masi), and assess the physiological parameters before, during, and after the invasive intubation on a swine model.

\section{Methods}

\section{Methodological design}

The primary aim of this study is to determine the safety and efficacy of acute exposure (6h) to mechanical ventilation with Masi in healthy swine, and to identify any signs of barotrauma as a result of 
this exposure. A longitudinal pre-clinical study was designed to assess the performance of biological parameters during mechanical ventilation in anesthetized pigs (Fig. 1). The sample size calculation was performed in line with the Animal welfare requirements section (part 2) from ISO 10993 - "Biological evaluation of medical devices". Therefore, to minimize both the number of animals required and any pain or distress, a hierarchical approach was implemented. Accordingly, a preliminary study with no more than two swine under mechanical ventilation for one hour was performed. Promising results obtained during this test encourage us to continue with the first group of four animals exposed for $6 \mathrm{~h}$ to mechanical ventilation. The percentage of swine able to breathe autonomously after connection to the mechanical ventilator for 6 hours was the determining factor to continue the trial with four additional swine. Thus, it was stablished a priori that lower than $50 \%$ percent of successful outcomes would be considered a failure. The statistical validity of the sample assumed a $95 \%$ confidence level, $5 \%$ margin of error, and about $99.5 \%$ of swine that breathe autonomously after six hours of mechanical ventilation with Masi.

A preliminary study was crucial to determine baseline physiological safety in a short exposure period (1 hour) to ventilation. Positive outcomes for the preliminary study followed testing for a longer exposure time (6 hours) with an additional number of animals (4 animals). Positive outcomes for the first group were followed by a second group of animals to obtain statistical power. Otherwise, in case any lesions were observed in pig \#0_1 pathological analysis, to rule out an intrinsic defect, it would have been necessary to repeat the test with just one animal (pig \#0_3). If damage persists, it is appropriate to associate traumatic lesions with Masi exposure, and consequently cancel the preclinical trial.

\section{Ethics}

All pre-clinical protocols carried out in this project were performed in accordance with the Animal Research: Reporting In Vivo Experiments (ARRIVE) guidelines and were approved by the Committee on Research Ethics for Life Sciences and Technologies at Pontificia Universidad Catolica del Peru (Protocol No002-2020-CEICVyTech/PUCP).

\section{Animals}

The study used young animals from a modern and commercial pig farm (Universidad Nacional Agraria La Molina, Lima, Peru). For this purpose, we collected standard physiological parameters for different studies involving swine as summarized in Table 1. 
Table 1

Summary of standardized physiological values on cardiorespiratory parameters in swine.

\begin{tabular}{|c|c|c|c|c|}
\hline Characteristics & Mean & SD & $\mathbf{n}$ & References \\
\hline Rectal Temperature $\left({ }^{\circ} \mathrm{C}\right)$ & 38.9 & 0.6 & 30 & [14] \\
\hline $\mathrm{pH}$, in arterial blood & 7.414 & 0.054 & 86 & {$[14-17]$} \\
\hline $\mathrm{HCO}_{3}^{-}(\mathrm{mmHg})$ in arterial blood & 23.7 & 7.7 & 38 & {$[14,17]$} \\
\hline Lactate $(\mathrm{mmol} / \mathrm{l})$ in arterial blood & 1.46 & 0.46 & 25 & [16] \\
\hline BEecf $(\mathrm{mmol} / \mathrm{l})$ in arterial blood & 0.06 & 6.60 & 38 & {$[14,17]$} \\
\hline $\mathrm{SaO}_{2}(\%)$ & 98.2 & 1.67 & 56 & {$[15-17]$} \\
\hline $\mathrm{PaO}_{2}(\mathrm{mmHg})$ & 161.9 & 36.4 & 86 & {$[14-17]$} \\
\hline $\mathrm{PaCO}_{2}(\mathrm{mmHg})$ & 39.5 & 8.9 & 86 & {$[14-17]$} \\
\hline Respiratory rate (breaths/min) & 31 & 8.8 & 30 & [14] \\
\hline Heart rate (beats/min) & 114 & 14.1 & 53 & {$[14,15]$} \\
\hline Cardiac output (I/min) & 5.542 & 1.114 & 23 & [15] \\
\hline Hemoglobin (g/dl) & 8.5 & 1.74 & 25 & [16] \\
\hline Hematocrit (\%) & 25.0 & 5.1 & 25 & [16] \\
\hline \multicolumn{5}{|c|}{$\begin{array}{l}\text { Data was reported as mean } \pm \text { standard deviation. adapted from data available at reference } 14,15,1 \\
\text { and, } 17 \text {, as described above. SD: standard deviation, } \mathrm{pH} \text { : potential of hydrogen, } \mathrm{HCO}_{3}^{-}: \text {bicarbonate } \\
\text { ion, } \mathrm{BEecf} \text { : base excess in the extracellular fluid compartment, } \mathrm{SaO}_{2} \text { : oxygen saturation in arterial } \\
\text { blood, } \mathrm{PaO}_{2}: \text { oxygen pressure in arterial blood, } \mathrm{PaCO}_{2}: \text { carbon dioxide pressure in arterial blood, } \\
\mathrm{ETCO}_{2}: \text { end-tidal carbon dioxide concentration. }\end{array}$} \\
\hline
\end{tabular}

A total of eight animals ( 7 males and 1 female), Yorkshire $x$ Landrace swine, three to four months old weighing 40-60 kg were used in this study as described in Table 2. 
Table 2

Summary of general baseline animal health data from animals under study.

\begin{tabular}{|c|c|c|c|c|c|c|}
\hline Animal & $\begin{array}{l}\text { Weigh } \\
(\mathrm{kg})\end{array}$ & $\begin{array}{l}\text { Age } \\
\text { (months) }\end{array}$ & Sex & $\begin{array}{l}\text { Media compliance } \\
\left(\mathrm{ml} / \mathrm{cmH}_{2} \mathrm{O}\right)\end{array}$ & $\begin{array}{l}\text { Hemoglobin } \\
(\mathrm{g} / \mathrm{dl})\end{array}$ & $\begin{array}{l}\text { Hematocrit } \\
\text { (\%) }\end{array}$ \\
\hline \#1_1 & 41.0 & 3.0 & Male & 39 & 10.2 & 31.5 \\
\hline \#1_2 & 45.5 & 3.0 & Male & 44 & 9.4 & 28.7 \\
\hline \#1_3 & 50.0 & 3.5 & Male & 32 & 9.1 & 26.9 \\
\hline \#1_4 & 49.0 & 3.5 & Male & 39 & 10.5 & 31.3 \\
\hline \#1_5 & 46.5 & 3.5 & Female & 39 & 11.1 & 33.2 \\
\hline \#1_6 & 52.0 & 3.5 & Male & 38 & 10.0 & 31.6 \\
\hline \#1_7 & 56.0 & 4.0 & Male & 39 & 10.3 & 33.1 \\
\hline \#1_8 & 50.0 & 4.0 & Male & 37 & 10.1 & 32.3 \\
\hline
\end{tabular}

The pigs were housed in the animal facilities of the School of Veterinary Medicine at the Universidad Nacional Mayor de San Marcos (UNMSM, Lima, Peru). These animals were kept in the facilities for 3-4 days to allow acclimatization and clinical observation by Veterinarians. The animals received commercial food twice a day (approximately $2 \mathrm{~kg} /$ day), and water ad libitum. Pigs were apparently healthy; no clinical signs were seen or reported by the time of the trial. Hematological and biochemical test, as well as ultrasound images from heart and lungs, were performed. It was considered at that time that all of the animals were in good health to participate in biological evaluations for the Masi ventilator.

Accordingly, Fig. 2 summarizes the experimental timeline of each intervention, considering sedation and deep anesthesia protocols, as well as the interventional procedures for sampling and data collection. These procedures will be described in detail below.

The diagram shows the stages carried out for drugs supplying, the interventions performed on animals for the coupling of the Masi mechanical ventilator, the sampling periods, as well as the procedures after the removal of the mechanical ventilator. PC-CMV: Pressure Control-Continuous Mandatory Ventilation, VC-CMV: Volume Control-Continuous Mandatory Ventilation, PSV: pressure support ventilation, $\mathrm{t}_{0-7}$ : blood sample collection time.

\section{Premedication}

Premedication with sedative drugs and anesthesia protocols were performed as previously described by Clauss and co-workers [18]. Animals were food-deprived for 12 hours before the procedures to avoid both gastric dilatation and vomiting. The access to water was also restricted 2-6 hours prior to the process begins. On the morning intervention, swine were sedated with ketamine $20 \mathrm{mg} / \mathrm{kg}+$ Azaperone $1 \mathrm{mg} / \mathrm{kg}$ via intramuscular in the neck, behind the ear. Later, the animals were placed on the work table and receive 
about 5 minutes of oxygen flow at $6-8 \mathrm{l} / \mathrm{min}$ through a mask. The marginal ear vein was catheterized for the administration of both fluids and drugs. The saline solution $0.9 \%(\mathrm{p} / \mathrm{v})$ was administered at 5 $\mathrm{ml} / \mathrm{kg} / \mathrm{h}$, and also depending of pig clinical evaluation. Ophthalmic ointment was applied to prevent corneal drying.

\section{Anesthesia induction}

Propofol $0.5-1 \mathrm{mg} / \mathrm{kg}$ combined with midazolam $0.25 \mathrm{mg} / \mathrm{kg}$ were administered to induce anesthesia in the swine through a catheterized ear vein. Anesthetics plane was maintained by a combination of propofol $2.5-5 \mathrm{mg} / \mathrm{kg} / \mathrm{h}$ during the intervention, in addition to fentanyl $2.5 \mu \mathrm{g} / \mathrm{kg} / \mathrm{h}$ if required. After anesthetizing the animal, the femoral artery was dissected to allow taking serial blood samples; this catheter was maintained with sodium heparin solution $5000 \mathrm{IU} / \mathrm{ml}$. Then, animals were placed in ventral decubitus and intubated with a 6-7 mm endotracheal tube, according to animal weight.

Deep anesthesia was monitored by Veterinarians and maintained in the proper range. While inducing anesthesia, heart and respiratory rates were measured with a stethoscope. Electrocardiograms (EKG) were performed to monitor cardiovascular responses during the intervention. In addition to vital signs, anesthetic depth was constantly assessed by jaw tonicity and reflex (corneal touch, pedal flexion, coronary band pinch).

After six hours of mandatory mechanical ventilation with Masi, deep anesthesia was suspended and swine were switched to a non-mandatory ventilation mode (pressure-support ventilation, PSV). The ability of animals to breath autonomously were monitored until three complete breaths were performed using an apnea time of 1 minute before proceeding with the euthanasia.

\section{Lung mechanics analysis}

After deep anesthesia was reached, animals were allowed 10 minutes to stabilize. Then, endotracheal intubation was performed in swine to connect the mechanical ventilator. An experienced veterinary anesthesiologist monitored the ventilatory parameters by capnography and capnometry. Ventilator parameters were calculated to obtain tidal volumes of about $6 \mathrm{~mL} / \mathrm{kg}$; and set positive end expiratory pressure (PEEP) between 7-9 $\mathrm{cmH}_{2} \mathrm{O}$, and an inspiration-expiration ratio (I:E) about 1:2 with tidal volumes between 450 to $550 \mathrm{~mL}$. According to literature, our protocol provided a protective ventilation once it considered low tidal volume, and high PEEP [19]. Once the parameters were stabilized, the constant pressure controlled ventilator mode (PC-CMV) was used for the firsts three hours and then the operating mode was replaced for a constant volume control (VC-CMV) for additional three hours.

\section{Assessment of physiological parameters}

Complete hemogram and serum biochemistry analysis were performed to determine their physiological conditions prior to the intervention. The ProCyte Dx hematological analyzer (Idexx Laboratories) and Catalyst One (Idexx Laboratories) were utilized to achieve this purpose, respectively. 
Oxygen saturation, blood pressure, respiratory and heart rate were constantly monitored with a veterinary multiparametric monitor through a cuff placed in the hind leg. Temperature was also registered with a rectal probe and maintained above $36^{\circ} \mathrm{C}$ during sedation using infrared heating lamps when necessary.

Femoral artery catheterization was performed managing lidocaine $\mathrm{HCl} 2 \%$ locally, arterial samples were collected in a $1 \mathrm{ml}$ heparinized syringe and immediately analyzed using the iSTAT system CG4 + cartridge (Abbott Point of Care Inc). Base excess in the extracellular fluid compartment (BEecf), bicarbonate $\left(\mathrm{HCO}_{3}{ }^{-}\right)$, arterial oxygen saturation $\left(\mathrm{SaO}_{2}\right)$, lactate, $\mathrm{pH}$, arterial pressure of oxygen $\left(\mathrm{PaO}_{2}\right)$, and arterial pressure of carbon dioxide $\left(\mathrm{PaCO}_{2}\right)$ were measure in arterial blood by gas analyzer. Heart and respiratory rates were determined by auscultation with a stethoscope. End-tidal carbon dioxide $\left(\mathrm{ETCO}_{2}\right)$ were measured with a capnograph Respironics LoFlo Side-Stream $\mathrm{CO}_{2}$ Sensor Module (@Philips). Arrhythmias presence was monitored using the computerized electrocardiogram EG PC $(T E B \otimes)$. Echocardiography and lung ultrasonography were performed with the scanner MyLab ${ }^{\mathrm{TM}} 30$ Vet Gold (Esaote S.p.A.) ultrasound machine.

Samples and data were collected in specific ranks of time. Prior to the anesthesia, a baseline $\left(\mathrm{t}_{0}\right)$ sample was considered for each swine. Once mechanical ventilation with Masi starts, seven additional times $\left(t_{1}\right.$ $\left.{ }_{7}\right)$ to collect samples and data were considered. The $t_{1-7}$ period was carried out according to the following pattern: $15 \mathrm{~min}\left(\mathrm{t}_{1}\right), 30 \mathrm{~min}\left(\mathrm{t}_{2}\right), 60 \mathrm{~min}\left(\mathrm{t}_{3}\right), 120 \mathrm{~min}\left(\mathrm{t}_{4}\right), 180 \mathrm{~min}\left(\mathrm{t}_{5}\right), 240 \mathrm{~min}\left(\mathrm{t}_{6}\right)$, and $300 \mathrm{~min}$ $\left(\mathrm{t}_{7}\right)$.

\section{Euthanasia, necropsy and histopathology}

Pharmacological euthanasia was performed in accordance with the ethical regulation for the humane treatment of experimental animals. Hence, animals received an overdose of sodium pentobarbital (150 $\mathrm{mg} / \mathrm{kg}$ ) intravenously [20]. Animal death was confirmed by auscultation of heart and respiratory rate with a stethoscope. Necropsy was performed following standard procedures for pigs [21]. Macroscopic signs of lesions in the brain, liver, kidney, heart, and lungs were evaluated. Furthermore, samples were taken for histopathological studies of the brain, heart, kidney, liver, and lungs to look for evidence of barotrauma or acute hypoxia.

\section{Statistical analysis}

Statistic 10.0 software (StatSoft Europe, Hamburg 22301, Germany) was used for the statistical analysis. For descriptive purposes, mean, median, standard error of the mean, first and third quartile, minimum and maximum values were calculated from different sampling points. The absence of normal distribution was determined by Shapiro Wilk's W test. Grubbs's test was performed to determine significant outliers in our data (GraphPad QuickCalcs, www.graphpad.com). In addition, Friedman non parametric test for repeated measures was performed to compare ranks over sampling points. Then, Wilcoxon Matched Pairs test was performed to compare between intervals and assess median variations. This statistical method was used to compare adjacent time periods, as well as to contrast each experimental period with the baseline. Non-parametric Spearman rank order correlation analysis was performed to assess 
relationship between quantitative variables. Graphs were plotted in GraphPad Prism 6.0 (GraphPad Software, California 92108, USA). On the other hand, baseline parameters were compared with literature data using Student T-test, assuming that the data from all of the other studies were also normal as our data was. Finally, for all the assays statistical significance was attributed to $p$-value $\leq 0.05$.

\section{Results}

Hematological analysis performed in swine during housing period exhibited that physiological measurements were within standard normal limits. Nevertheless, pre-intervention echocardiograms showed that two of the patients (pig \#2 and \#5) presented a sub-clinical heart valve pathology. Later, histopathological analysis determined a chronic inflammation of the lungs that might be attributed to an enzootic pneumonia of high prevalence in Peru caused by Mycoplasma hyopneumoniae (Table S1, Figure S3B). However, these chronic pathologies would not interfere with the observation of barotrauma acute lung lesions that are of interest in our experimental design.

The average for swine's cardiorespiratory and blood biochemistry parameters taken at the initial sampling procedure $\left(\mathrm{t}_{0}\right)$ are displayed in Table 3. No significant differences were found in most of the studied parameters in comparison with previous data for swine under sedation (Table 1), with the exception of $\mathrm{HCO}_{3}{ }^{-}, \mathrm{BEecf}, \mathrm{SaO}_{2}$, and $\mathrm{PaO}_{2}$ levels.

\section{Table 3. Baseline values for cardiorespiratory parameters in swine.}




\begin{tabular}{|c|c|c|c|c|c|c|c|c|c|}
\hline Parameters & $\mathrm{n}$ & Mean & Min. & $Q_{1}$ & Median & $Q_{3}$ & Max. & SEM & $\begin{array}{l}\text { T-test } \\
\text { p-value }\end{array}$ \\
\hline Temperature $\left({ }^{\circ} \mathrm{C}\right)$ & 8 & 36.6 & 35.9 & 36.3 & 36.7 & 36.8 & 37 & 0.1 & 0.157 \\
\hline $\mathrm{pH}$ & 8 & 7.395 & 7.329 & 7.368 & 7.410 & 7.422 & 7.431 & 0.013 & 0.261 \\
\hline $\mathrm{HCO}_{3}^{-}(\mathrm{mmHg})$ & 8 & 32.3 & 29.8 & 30.6 & 32.3 & 33.8 & 34.8 & 0.6 & 0.001 \\
\hline Lactate $(\mathrm{mmol} / \mathrm{l})$ & 8 & 1.41 & 0.63 & 1.23 & 1.36 & 1.80 & 1.88 & 0.15 & 0.822 \\
\hline BEecf (mmol/l) & 8 & 7.2 & 5 & 5.5 & 7 & 9 & 10 & 0.7 & 0.003 \\
\hline $\mathrm{SaO}_{2}(\%)$ & 8 & 100 & 100 & 100 & 100 & 100 & 100 & 0.0 & $<0.0001$ \\
\hline $\mathrm{PaO}_{2}(\mathrm{mmHg})$ & 8 & 334 & 169 & 278 & 322 & 387.5 & 529 & 37.6 & $<0.0001$ \\
\hline $\mathrm{PaCO}_{2}(\mathrm{mmHg})$ & 8 & 52.9 & 45.1 & 48.3 & 52.6 & 57.6 & 61.4 & 2.0 & 0.218 \\
\hline $\mathrm{ETCO}_{2}(\mathrm{mmHg})$ & 8 & 33.7 & 31 & 32 & 34 & 35.5 & 36 & 0.7 & * \\
\hline $\begin{array}{l}\text { Respiratory rate } \\
\text { (breaths/min) }\end{array}$ & 8 & 37.1 & 20 & 28.5 & 38 & 44 & 56 & 4.1 & 0.266 \\
\hline $\begin{array}{l}\text { Heart rate } \\
\text { (beats/min) }\end{array}$ & 8 & 85.4 & 69 & 77.5 & 83.5 & 93.5 & 105 & 4.3 & 0.752 \\
\hline $\begin{array}{l}\text { Cardiac output } \\
(\mathrm{ml} / \mathrm{min})\end{array}$ & 8 & 5.892 & 3.203 & 4.752 & 6.087 & 7.040 & 8.171 & 0.586 & 0.146 \\
\hline
\end{tabular}

After sedation but prior to the induction of deep anesthesia required for connection with Masi mechanical ventilator, cardiorespiratory and physiological parameters were collected for the animals to be used as baseline values. Min.: minimum value, Max.: maximum value, $Q_{1}$ : lower quartile, $Q_{3}$ : upper quartile, $S E M$ : standard error of the mean, $\mathrm{pH}$ : potential of hydrogen, $\mathrm{HCO}_{3}$ : bicarbonate ion, $\mathrm{BEecf:}$ : base excess in the extracellular fluid compartment, $\mathrm{SaO}_{2}$ : arterial oxygen saturation, $\mathrm{PaO}_{2}$ : arterial oxygen pressure, $\mathrm{PaCO}_{2}$ : arterial carbon dioxide pressure, $\mathrm{ETCO}_{2}$ : end-tidal carbon dioxide, *no reference data available. T-test performed to analyze differences between previous register physiological values (Table 1) and our baseline data set, significant differences were established at $p$-value $<0.05$

According to Wilcoxon test, perceived in Figure 3, the levels of $\mathrm{SaO}_{2}, \mathrm{PaO}_{2}$, and BEecf dropped drastically when assessed at $\mathrm{t}_{1}$, with respect to $\mathrm{t}_{0}$. In addition, variations in $\mathrm{pH}$ and $\mathrm{PaCO}_{2}$ values were observed when contrasting $t_{1}$ and $t_{2}$. Although some of the values dropped from $t_{0}$ to $t_{1}$, most of them increased, even restored, in the following measures. Based on these differences, $t_{1}$ was considered as a temporary period of transition from sedation to deep anesthesia, with limited relevance on the effect of ventilation. Therefore, $t_{1}$ values were not considered when summarizing the physiological effects attributed to the use of the Masi mechanical ventilator shown in Table 4. 
Table 4. Summary of statistical distribution for arterial blood biochemistry values $\left(t_{2-7}\right)$.

\begin{tabular}{|c|c|c|c|c|c|c|c|c|c|}
\hline Parameters & Mean & SEM & Min. & $Q_{1}$ & Median & $Q_{3}$ & Max. & $\mathrm{n}$ & $\begin{array}{l}\text { Friedman } \\
\text { test } \\
\text { p-value }\end{array}$ \\
\hline $\mathrm{pH}$ & 7.455 & 0.010 & 7.193 & 7.418 & 7.473 & 7.506 & 7.557 & 48 & 0.744 \\
\hline $\mathrm{HCO}_{3}^{-}(\mathrm{mmHg})$ & 31.3 & 0.3 & 25.3 & 30.5 & 31.6 & 32.5 & 34.6 & 48 & 0.003 \\
\hline $\begin{array}{l}\text { Lactate } \\
(\mathrm{mmol} / \mathrm{l})\end{array}$ & 2.29 & 0.33 & 0.57 & 1.05 & 1.34 & 1.94 & 9.21 & 48 & 0.003 \\
\hline BEecf $(\mathrm{mmol} / \mathrm{l})$ & 7.3 & 0.4 & 0 & 6 & 8 & 9 & 11 & 48 & 0.021 \\
\hline $\mathrm{SaO}_{2}(\%)$ & 99.5 & 0.3 & 88 & 100 & 100 & 100 & 100 & 48 & 0.335 \\
\hline $\mathrm{PaO}_{2}(\mathrm{mmHg})$ & 203 & 7.7 & 69 & 164 & 204 & 247.5 & 290 & 48 & 0.014 \\
\hline $\mathrm{PaCO}_{2}(\mathrm{mmHg})$ & 44.8 & 0.9 & 34.6 & 40.5 & 43.6 & 48.2 & 72.4 & 48 & 0.235 \\
\hline $\mathrm{ETCO}_{2}$ & 32.5 & 0.3 & 27 & 32 & 33 & 34 & 36 & 48 & 0.002 \\
\hline
\end{tabular}

Descriptive statistics like mean, standard error of the mean (SEM), minimum (Min.), 25th percentile $\left(\mathrm{Q}_{1}\right)$, median, 75th percentile $\left(\mathrm{Q}_{3}\right)$, maximum (Max.), and number of observations $(\mathrm{n})$ for each cardiopulmonary parameter measure over the six hours of mechanical ventilation with Masi $\left(t_{2-7}\right)$ were summarized below. Significant differences when using the Friedman test to analyze differences among $t_{2-7}$ were established at $\mathrm{p}$-value $<0.05 . \mathrm{pH}$ : potential of hydrogen, $\mathrm{HCO}_{3}$ : : bicarbonate ion, $\mathrm{BEecf}$ : base excess in the extracellular fluid compartment, $\mathrm{SaO}_{2}$ : arterial oxygen saturation, $\mathrm{PaO}_{2}$ : arterial oxygen pressure, $\mathrm{PaCO}_{2}$ : arterial carbon dioxide pressure, $\mathrm{ETCO}_{2}$ : end-tidal carbon dioxide.

Descriptive statistics for the physiological parameters analyzed during the use of the Masi mechanical ventilator $\left(\mathrm{t}_{2-7}\right)$ are described in Table 4 . Complete data is provided in supplementary material Table S2. The rank comparison performed through Friedman's non-parametric test for repeated measures evidenced significant differences in $\mathrm{HCO}_{3}{ }^{-}$, lactate, $\mathrm{BEecf,} \mathrm{PaO}_{2}$, and $\mathrm{ETCO}_{2}$ levels over time. To identify the variability points, the Wilcoxon test by pairs was performed. Among the sampling points $t_{2-7}$, both $\mathrm{HCO}_{3}{ }^{-}$and $\mathrm{BEecf}$ values gradually increased over time, lactate concentrations decrease, meanwhile $\mathrm{PaO}_{2}$ and $\mathrm{PaCO}_{2}$ remained fluctuating (Figure 4). Since comparisons were performed using median values, outlier data should not interfere with the analysis.

Data from physiological parameters documented during exposure to Masi mechanical ventilation $\left(\mathrm{t}_{2-7}\right)$ were contrasted, one by one, with baseline values $\left(\mathrm{t}_{0}\right)$. Table 5 shows us the dimension of the differences found through the z-score, and the statistical significance supported by the Friedman test. 
Table 5. Changes in arterial blood biochemical parameters per time point adjusted to baseline.

\begin{tabular}{|llllllll|}
\cline { 1 - 5 } Parameters & \multicolumn{1}{l}{ Time points } & & & & \\
\end{tabular}

Statistical differences between the medians of the data obtained at each sampling point $\left(t_{2-7}\right)$ and the median of the baseline data $\left(\mathrm{t}_{0}\right)$ were analyzed using the Friedman test. The table shows the $\mathrm{z}$-score ( $\mathrm{p}$ value). $\mathrm{pH}$ : potential of hydrogen, $\mathrm{HCO}_{3}^{-}$: bicarbonate ion, $\mathrm{BEecf}$ : base excess in the extracellular fluid compartment, $\mathrm{SaO}_{2}$ : arterial oxygen saturation, $\mathrm{PaO}_{2}$ : arterial oxygen pressure, $\mathrm{PaCO}_{2}$ : arterial carbon dioxide pressure, $\mathrm{ETCO}_{2}$ : end-tidal carbon dioxide.

According to Table 5, some analyzed parameters suffered initial variations, which were overcome in time until reaching baseline values. For instance, the $\mathrm{HCO}_{3}{ }^{-}$, which initially $\left(\mathrm{t}_{1}\right)$ suffered a drop in its concentration levels (Figure 3 ), gradually increased its concentration in arterial gases through $\mathrm{t}_{27}$ period (Figure 4). These progressive changes allowed to reduce the differences with baseline levels $\left(\mathrm{t}_{0}\right)$. Similarly, $\mathrm{ETCO}_{2}$ presented significant differences in contrast to baseline initially $\left(\mathrm{t}_{2}\right)$. Through its evolution over time, the differences in median values between experimental data and baseline were 
reduced. In addition, BEecf and lactate values underwent changes during the initial phase $\left(\mathrm{t}_{1}\right)$ that were recovered by $\mathrm{t}_{5}$. It is worth noting that changes in $\mathrm{pH}$ and $\mathrm{PaO}_{2}$ altered in the initial period with the mechanical ventilator never reached back to baseline levels. The experimental median values of $\mathrm{pH}\left(\mathrm{t}_{2-7} \mathrm{r}\right)$ showed significant differences from the baseline median $\left(t_{0}\right)$, excepting at $t_{2}$ and $t_{6}$. In the evolutionary graph for this parameter (Figure 3 ) it was observed that, despite the initial reduction in $\mathrm{pH}\left(\mathrm{t}_{1}\right)$, experimental values $\left(\mathrm{t}_{2-7}-7\right)$ tend to be higher than the basal ones. The $\mathrm{PaO}_{2}$ showed significant differences from baseline throughout the experimental time, suffering a dramatic fall at the beginning of the experimental protocol $\left(t_{1}\right)$ and it never recovered (Figure 3$)$. However, the variance between the experimental values ( $t_{2-7}$, exposure to Masi) and the baseline $\left(t_{0}\right)$ remains constant over time, neglecting the effect of fluctuations registered for this period ( $t_{2-7}$, Figure 4$)$. While $\mathrm{SaO}_{2}$ did not show significant differences at any time $\left(\mathrm{t}_{2-7}\right)$ when compared with basal values, fluctuations observed in $\mathrm{PaCO}_{2}\left(\mathrm{t}_{2-7}\right.$, Figure 4) produced significant variations between experimental and basal medians only at specific times, $t_{4}$ and $t_{5}$.

A Spearman correlation analysis between $\mathrm{ETCO}_{2}$ and $\mathrm{PaCO}_{2}$ was performed to determine possible effects on lung function that might by carried to blood biochemistry quality $[22,23]$. Spearman test indicates that there is no significant correlation between both variables (Figure 5).

Based on ultrasound images of lung (Figure S1) and heart (Figure S2), there were no alterations in the functioning of these organs that could indicate injuries related to the use of Masi mechanical ventilator. Furthermore, the histopathological analysis performed on the lung, brain, heart, liver and kidney did not show early lesions consistent with barotrauma or hypoxia. However, it was possible to recognize some tissue alterations in these organs, which suggest previous or chronic infection processes (Figure S3 and Table S1).

\section{Discussion}

Swine have anatomical similarities with humans, which make them a good experimental model for respiratory interventions $[10,11]$. However, production swine have been selected for larger thoracic cavities resulting in larger tidal volumes with uncertain repercussions on the functional differences from an anatomical and physiological point of view [24,25]. Medical education in Peru still uses swine as a model for surgical training. Therefore, there is significant experience implementing protocols for sedation and deep anesthesia similar to those applied by health personnel for intubation process in the Operating Room and ICU [26-28].

At initial conditions $\left(\mathrm{t}_{0}\right)$, prior to deep anesthesia and intubation, swine exhibit a good physiological management of gas airway exchange [29]. Despite the fact that most data were located within the rank of previously described standard physiological parameters, the distribution of our baseline data allowed to recognize statistically significant differences. For instance, our swine exhibit high measures of $\mathrm{PaO}_{2}$, as well as increased levels of $\mathrm{HCO}_{3}{ }^{-}, \mathrm{BEecf}$, and $\mathrm{ETCO}_{2}$. This notably changes are accompanied by milder 
variations (no statistically significant) which includes the decrease of heart rate and the increase of both $\mathrm{PaCO}_{2}$ and respiratory rate. Considering that samples at $\mathrm{t}_{0}$ were taken from sedated animals, hemodynamic alterations regarding the reduction of body inactivity and low corporal temperature might be considered. Thus, these conditions may be responsible for heart rate reduction [30]. Low blood ventilation per minute induce the accumulation of $\mathrm{HCO}_{3}{ }^{-}$and $\mathrm{CO}_{2}$, and subsequent rise of $\mathrm{PaCO}_{2}, \mathrm{BEecf}$ and decrease of $\mathrm{ETCO}_{2}$ parameters. This condition is known as metabolic alkalosis [31,32]. Increasing of respiratory rate and $\mathrm{PaO}_{2}$ may explain a compensatory measure to improve oxygen availability. It is noteworthy to indicate that once under the effects of deep anesthesia and connected to the mechanical ventilator, the respiratory rate of the animal is restored and the values returned closer to the average in literature.

Once under the Masi mechanical ventilation system, the control of the respiratory rate and the tidal volume for protective ventilation [19,33], as well as individualized setting according to swine compliance, allowed as primary outcome the improvement of oxygenation parameters in most patients. For instance, those animals that initially shown $\mathrm{PaO}_{2}$ levels far above the average, reduced their values closer to the standard. Consequently, levels of $\mathrm{PaCO}_{2}$ diminished in short time in contrast to baseline, demonstrating efficient carbon dioxide elimination. These parameters related to oxygen uptake, $\mathrm{PaO}_{2}$ and $\mathrm{PaCO}_{2}$, remained almost constant over time. $\mathrm{PaO}_{2}$ showed slight oscillatory behavior. Accumulation of $\mathrm{PaCO}_{2}$, usually associated with an ineffective gas exchange process [34], was not observed during our interventions.

Additionally, other parameters to assess the correct oxygen transportation and carbon dioxide elimination during airflow are $\mathrm{SaO}_{2}$ and $\mathrm{ETCO}_{2}$, respectively [22,23]. According to our results, $\mathrm{SaO}_{2}$ remained at high levels ( 100\%) at all sampling times, including the baseline. It is possible that the body temperature of $37^{\circ} \mathrm{C}$ in patients during experimental protocol, which is relatively low for the species (normal body temperature $\left.=39^{\circ} \mathrm{C}\right)$ but not enough to induce hypothermia $\left(32-34^{\circ} \mathrm{C}\right)[35,36]$, slightly contribute to enhance oxygen affinity to hemoglobin keeping optimum saturation levels [37,38]. $\mathrm{ETCO}_{2}$ levels were found below the predicted average but its value increases over time, getting closer to the range suggested in the literature. These maximum levels of $\mathrm{ETCO}_{2}$ complemented with the decrease of $\mathrm{PaCO}_{2}$ during the interventions corroborate the correct elimination of carbon dioxide as a waste product of cellular metabolism [23]. Furthermore, this increase in ETCO2 values is favorable since previous work described that slightly high levels of $\mathrm{ETCO}_{2}$ in humans could be related to decreased odds of lung injury $[39,40]$. Therefore, the upper distribution of $\mathrm{ETCO}_{2}$ values is consistent the absence of lung tissue damage. Similarly, the establishment of uncorrelated behavior between the $\mathrm{PaCO}_{2}$ and $\mathrm{ETCO}_{2}$ variables represent an additional parameter to suggest no tissue damage $[23,41,42]$.

Likewise, variations in $\mathrm{PaCO}_{2}$ directly affect $\mathrm{pH}$ and $\mathrm{HCO}_{3}{ }^{-}$values. Hypocapnia (low levels of $\mathrm{PaCO}_{2}$ ) triggered by hyperventilatory processes reduces the availability of $\mathrm{CO}_{2}$ molecules for the production of $\left[\mathrm{HCO}_{3}{ }^{-}\right]$and $\left[\mathrm{H}^{+}\right]$. The reduction of these ions leads to an increase in serum $\mathrm{pH}$ levels, phenomenon known 
as acidosis. Conversely, hypercapnia (high levels of $\mathrm{PaCO}_{2}$ ) leads to lowering serum $\mathrm{pH}$ levels, alkalosis $[43,44]$. During the use of Masi mechanical ventilator, there was a weakly, but no statistic significant, reduction of $\mathrm{PaCO}_{2}$ at the beginning. This event was reflected immediately in the decrease of $\mathrm{HCO}_{3}{ }^{-}$and increase of $\mathrm{pH}$ values. Although $\mathrm{pH}$ values in humans are around 7.4, normal values in swine are between 7.45 - 7.55 [17]. Therefore, the second outcome achieved by Masi mechanical ventilator is the proper control of acid-base equilibrium.

Variations on serum lactate concentration may also influence in $\mathrm{pH}$ imbalance [43]. Lactate is a common cellular product from anaerobic respiration, in healthy conditions the clearance of lactate is managed by the liver though a process known as gluconeogenesis. Lactate accumulation in blood is usually related to inefficient perfusion, liver failure or tissue damages, and in some cases is considered a predictor of mortality in patients $[40,45]$. In this sense, swine exposed to Masi mechanical ventilation exhibited a reduction of serum lactate concentrations over time. Non-accumulation of lactate indicates good perfusion in tissues, and prompts physiological integrity of distal organs. Hence, Masi mechanical ventilator guarantees, as a third outcome, an adequate gas exchange in tissues, allowing the adequate lactate metabolism and preventing its accumulation. Moreover, in contrast to the gradual decrease of lactate in serum, $\mathrm{HCO}_{3}{ }^{-}$levels increased steadily as a compensatory mechanism to keep $\mathrm{pH}$ in balance [46]. Furthermore, BEecf measures the acid-base disturbances and have mathematically a direct relationship with $\mathrm{HCO}_{3}{ }^{-}$[47], therefore slightly increased values over time mirror $\mathrm{HCO}_{3}{ }^{-}$variations.

During the experimental procedures, some patients exhibited outlying physiological parameters from the group mean, these patients were pig \#2 and \#5. Cases of metabolic acidosis induced by the use of propofol during anesthesia have been previously described [48]. This metabolic acidosis is characterized by the increase in lactate levels, and the reduction of $\mathrm{BEecf}$ and $\mathrm{HCO}_{3}{ }^{-}$in blood, which lead to $\mathrm{pH}$ decline [48]. Likewise, it has been found that there is a direct relationship between the levels of $\mathrm{HCO}_{3}{ }^{-}$and $\mathrm{ETCO}_{2}$ [49]. In accordance to these clinical characteristics, the alterations observed in the hemodynamic parameters of our patients described a mild case of metabolic acidosis. While the causes of this disorder remains unclear, it has been suggested that some subclinical alterations in distal organs could be a risk factor, suggesting that during acidosis stress these alterations may become harder to compensate $[48,50]$. According to histopathological analysis, both swine \#2 and \#5 presented mild kidney disturbance, and severe pulmonary alteration, but neither have early hypoxic lesions. Swine \#2 also presented minor liver compromise. Therefore, our observations on arterial blood biochemistry effects are more likely to be connected to increased risk of propofol-mediated metabolic acidosis due to underlying pathologies rather than as a result of the mechanical ventilation.

PSV was largely described as a successful tool to validate the ability to breath autonomously previous to the endotracheal tube removal in patients under mechanical ventilation [51,52]. PSV capacity to predict a successful extubation procedure ( $85 \%)$, as well as its ability to maintain stable hemodynamic parameters have been previously described [51,53]. However, in addition to the device support, some physiological characteristics are related to the probability of a good recovery from assisted ventilation, 
avoiding reintubation cases $[51,52]$. In our attempt to reduce unnecessary animal suffering, we monitor the autonomic respiratory capacity in sedated animals. In this way, we observed that after the use of Masi mechanical ventilator, all the animals were able to recover their spontaneous breathing.

Finally, the physiological changes produced during the use of the mechanical ventilator cause stress at the lung, but can also affect distant organs. Therefore, mechanical ventilators could produce functional alterations and even injuries in heart, liver, kidney and brain [54,55]. For this reason, and as a final outcome, the postmortem analysis certified the absence of both acute tissue damage or barotrauma signals due to the use of Masi. Thus, pathology studies corroborate what was expected according to the previously described biological indicators, such as slightly elevated levels of $\mathrm{ETCO}_{2}$ and the noncorrelation between $\mathrm{ETCO}_{2}$ and $\mathrm{PaCO}_{2}$.

\section{Conclusions}

In this study, we demonstrate that Masi mechanical ventilator allows to preserve patient physiological parameters within normal ranges during acute exposure (6 hours). Our data shows successful control of blood biochemistry mechanisms involved with oxygenation supply and carbon dioxide removal including: Oxygen uptake $\left(\mathrm{PaO}_{2}, \mathrm{PaCO}_{2}\right)$, carbon dioxide release $\left(\mathrm{ETCO}_{2}\right)$, oxygen transport $\left(\mathrm{SaO}_{2}\right)$, tissue perfusion (lactate), acid-base balance $\left(\mathrm{HCO}_{3}{ }^{-}, \mathrm{pH}\right)$. Likewise, the post-mortem study of critical organs and histopathological observations present no evident signs of barotrauma caused by the use of the Masi mechanical ventilator. These preclinical data, added to the correct yield of Masi throughout the tests to measure: safety, performance, compatibility, functionality, and software verification, allow to predict its adequate functioning during longer exposure times. Therefore, Masi allows the regulation of body gas exchange in a similar way as shown for other commercial mechanical ventilators.

\section{Declarations}

\section{Ethics approval and consent to participate}

All protocols carried out in this project were approved by the Committee on Research Ethics for Life Sciences and Technologies at Pontificia Universidad Catolica del Peru (Protocol No002-2020CEICVyTech/PUCP).

\section{Consent for publication}

Not applicable.

\section{Availability of data and materials}

The datasets used and/or analyzed during the current study are included in its publisher article and its supplementary information files. Additional information (i.e. images, or videos) that support the conclusions of the research are available from the corresponding author on reasonable request. 
$\underline{\text { Competing interests }}$

The authors declare that they have no competing interests.

\section{Funding}

This work is funded by the grant 055-2020-FONDECYT of the Peruvian Council of Science and Technology and private in-kind donations mentioned in our webpage: https://www.proyectomasi.pe/.

Authors' contributions

MMGC: Maryanne Melanie Gonzales Carazas

CMG: Cesar Miguel Gavidia

RDF: Roberto Davila Fernandez

JAVZ: Juan Alberto Vargas Zuñiga

ACP: Alberto Crespo Paiva

WB: William Bocanegra

JC: Joan Calderon

ES: Evelyn Sanchez

RP: Rosa Perales

BZ: Brandon Zeña

JFCl: Juan Fernando Calcina Isique

JR: Jaime Reategui

BCA: Benjamin Castañeda Aphan

FLC: Fanny L. Casado

MMGC: Reviewed literature, performed data analyses and wrote the first draft.

CMG: Reviewed literature, performed gross pathology analysis

RDF: Reviewed literature, performed ultrasound and ecocardiography

JAVZ: Reviewed literature, designed and performed anesthesia regime ACP: Reviewed literature, designed and performed anesthesia regime 
WB: Reviewed literature, performed anesthesia regime

JC: Performed anesthesia regime

ES: Performed blood chemistry analyses

RP: Reviewed literature, performed histopathology analyses

BZ: Performed anesthesia regime

JFCl: Assessed overall health pre-intervention and during intervention, assisted gross pathology

JR: Collected and analyzed ventilation data

BC: Conceived the study and supervised the collection and analysis of ventilation data

FC: Conceived the study, reviewed literature, assessed risk of bias, supervised the collection of data and statistical analyses.

All authors critically revised the manuscript and approved its final version.

\section{Acknowledgements}

The authors would like to thank to all the members of the Masi design team, especially to all of the collaborators working at the five institutions involved in this project (BREIN, DIACSA, EAT, and Zolid Design). Without all of their effort, professionalism and sacrifice while working steadily during the pandemic, this device would have not existed. We are thankful to Gisela Fernandez-Rivas Plata, Jordi Lopez-Tremoleda and Ricardo Hora for their insightful comments on study design.

\section{Abbreviations}

ARRIVE: Animal Research: Reporting In Vivo Experiments

BEecf: Base excess in the extracellular fluid compartment

COVID-19: Coronavirus disease 2019

EKG: Electrocardiogram

$\mathrm{ETCO}_{2}$ : End-tidal carbon dioxide concentration

$\mathrm{HCO}_{3}:$ : Bicarbonate ion

ICU: Intensive Care Units

I:E: Inspiration-expiration ratio 
Max.: Maximum value

MHRA: Medicines and Healthcare products Regulatory Agency

Min.: Minimum value

$\mathrm{n}$ : Number of observations

$\mathrm{PaCO}_{2}$ : Carbon dioxide pressure in arterial blood

PAHO: Pan American Health Organization

$\mathrm{PaO}_{2}$ : Oxygen pressure in arterial blood

PC-CMV: Pressure Control-Continuous Mandatory Ventilation

PEEP: Positive end expiratory pressure

$\mathrm{pH}$ : Potential of hydrogen

PSV: Pressure support ventilation

Q1: Lower quartile, 25th percentile

Q3: Upper quartile, 75th percentile

$\mathrm{SaO}_{2}:$ Oxygen saturation in arterial blood

SARS-CoV-2: Severe acute respiratory syndrome coronavirus 2

SD: Standard deviation

SEM: Standard error of the mean

$t_{0-7}$ : Blood sample collection time

VC-CMV: Volume Control-Continuous Mandatory Ventilation

WHO: World Health Organization

\section{References}

1. Xu X-K, Liu XF, Wu Y, Ali ST, Du Z, Bosetti P, et al. Reconstruction of transmission pairs for novel coronavirus disease 2019 (COVID-19) in Mainland China: estimation of superspreading events, serial interval, and hazard of infection. Clin Infect Dis. 2020;71:3163-7. 
2. Wang L, Didelot $X$, Yang J, Wong G, Shi Y, Liu W, et al. Inference of person-to-person transmission of COVID-19 reveals hidden super-spreading events during the early outbreak phase. Nat Commun. 2020;11:1-6.

3. Aquino M, Garrison C. Peru records first confirmed case of coronavirus, President Vizcarra says. Reuters. Lima; 2020 Mar 6;

4. Government of Peru. Supreme decret N 008-2020-SA. Lima: Ministry of Health; Mar 11, 2020 p. 1-4.

5. Chang J, Acosta A, Benavides J, Reategui J, Rojas C, Cook J, et al. Masi: A mechanical ventilator based on a manual resuscitator with telemedicine capabilities for patients with ARDS during the COVID-19 crisis. HardwareX. 2021;9:e00187.

6. Pan American Health Organization (PAHO/WHO). Technical specifications of medical devices for the management of COVID-19 cases in health services. Washington, D.C.; 2020 Mar.

7. Medicines and Healthcare products Regulatory Agency. Specification for ventilators to be used in UK hospitals during the coronavirus (COVID-19) outbreak. London; 2020 Mar.

8. Tharion J, Kapil S, Muthu N, Tharion JG, Kanagaraj S. Rapid Manufacturable Ventilator for Respiratory Emergencies of COVID-19 Disease. Trans Indian Natl Acad Eng. 2020;5:373-8.

9. Medicines \& Healthcare products Regulatory Agency. Specification for rapidly manufactured ventilator system (RMVS). London; 2020 Apr.

10. Judge EP, Hughes JML, Egan JJ, Maguire M, Molloy EL, O’Dea S. Anatomy and bronchoscopy of the porcine lung: A model for translational respiratory medicine. Am J Respir Cell Mol Biol. 2014;51:33443.

11. Perinel S, Pourchez J, Leclerc L, Avet J, Durand M, Prévôt N, et al. Development of an ex vivo humanporcine respiratory model for preclinical studies. Sci Rep. 2017;7:1-6.

12. Foster BE, Diaz-Abad M, Hudson AJ, Bedocs P, Doll DM, Lopez SA, et al. Invasive mechanical ventilation using a bilevel PAP ST device in a healthy swine model. Sleep Breath. 2020;24:1645-52.

13. Dhanani J, Pang G, Pincus J, Ahern B, Goodwin W, Cowling N, et al. Increasing ventilator surge capacity in COVID 19 pandemic: Design, manufacture and in vitro-in vivo testing in anaesthetized healthy pigs of a rapid prototyped mechanical ventilator. BMC Res Notes. 2020;13.

14. Marques JA, Moraes FCY de, Marques LC, Teixeira Neto FJ. Use of flunitrazepam and droperidol for tranquilization of swines. Ciência Rural. 1995;25:71-4.

15. Mahon RT, Ciarlone GE, Roney NG, Swift JM. Cardiovascular parameters in a swine model of normobaric hypoxia treated with 5-hydroxymethyl-2-furfural (5-HMF). Front Physiol. 2019;10:395.

16. Bekheit $M$, Bucur $P$, Vibert $E$, Andres $C$. The reference values for hepatic oxygen consumption and net lactate production, blood gasses, hemogram, major electrolytes, and kidney and liver profiles in anesthetized large white swine model. Transl Surg. 2016;1:95.

17. Biteli EGF, Nunes N, Lopes PCF, Silva PES, Ido CK, Silva HRA, et al. Blood gas analysis in pigs submitted to different concentrations of nitrous oxide or oxygen, under different ventilatory modalities. Arq Bras Med Vet e Zootec. 2019;71:35-43. 
18. Clauss S, Schüttler D, Bleyer C, Vlcek J, Shakarami M, Tomsits $P$, et al. Characterization of a porcine model of atrial arrhythmogenicity in the context of ischaemic heart failure. PLoS One. 2020;15.

19. Ferrando C, Soro M, Unzueta C, Suarez-Sipmann F, Canet J, Librero J, et al. Individualised perioperative open-lung approach versus standard protective ventilation in abdominal surgery (iPROVE): A randomised controlled trial. Lancet Respir Med. 2018;6:193-203.

20. AVMA. Guidelines for the euthanasia of animals. Schaumburg: American Veterinary Medical Association; 2020.

21. Swindle MM. Swine in the laboratory: Surgery, anesthesia, imaging, and experimental techniques. 2nd ed. Press C, editor. 2007.

22. Ebmeier SJ, Barker M, Bacon M, Beasley RC, Bellomo R, Chong CK, et al. A two centre observational study of simultaneous pulse oximetry and arterial oxygen saturation recordings in intensive care unit patients. Anaesth Intensive Care. 2018;46:297-303.

23. Mehta JH, Williams GW, Harvey BC, Grewal NK, George EE. The relationship between minute ventilation and end tidal $\mathrm{CO} 2$ in intubated and spontaneously breathing patients undergoing procedural sedation. PLoS One. 2017;12.

24. Williams K, Roman J. Studying human respiratory disease in animals - Role of induced and naturally occurring models. J Pathol. 2016;238:220-32.

25. Ibrahim Z, Busch J, Awwad M, Wagner R, Wells K, Cooper DKC. Selected physiologic compatibilities and incompatibilities between human and porcine organ systems. Xenotransplantation. 2006;13:488-99.

26. Poveda Jaramillo R, Dueñas Castell C, Ortiz Ruiz G. Rapid sequence intubation in the intensive care unit. Colomb J Anesthesiol. 2013;41:24-33.

27. Payen JF, Chanques G, Futier E, Velly L, Jaber S, Constantin JM. Sedation for critically ill patients with COVID-19: which specificities? One size does not fit all. Anaesth Crit Care Pain Med. 2020;39:341-3.

28. Granados Bullón LM, Castillo Lino JL. Guide to care procedure: Management of conventional airway and difficult airway in intensive care unit. Lima; 2018 Jul.

29. Tobin MJ. Basing respiratory management of COVID-19 on physiological principles. Am J Respir Crit Care Med. 2020;201:1319-20.

30. Davies $\mathrm{P}$, Maconochie I. The relationship between body temperature, heart rate and respiratory rate in children. Emerg Med J. 2009;26:641-3.

31. Peixoto AJ, Alpern RJ. Treatment of severe metabolic alkalosis in a patient with congestive heart failure. Am J Kidney Dis. 2013;61:822-7.

32. Galla JH. Metabolic Alkalosis. J Am Soc Nephrol. 2000;11:369-75.

33. Poston JT, Patel BK, Davis AM. Management of critically ill adults with COVID-19. JAMA - J Am Med Assoc. 2020;323:1839-41. 
34. Weber J, Schmidt J, Straka L, Wirth S, Schumann S. Flow-controlled ventilation improves gas exchange in lung-healthy patients- a randomized interventional cross-over study. Acta Anaesthesiol Scand. Blackwell Munksgaard; 2020;64:481-8.

35. Martini WZ. The effects of hypothermia on fibrinogen metabolism and coagulation function in swine. Metabolism. 2007;56:214-21.

36. Martini WZ, Pusateri AE, Uscilowicz JM, Delgado A V., Holcomb JB, Tyburski JG, et al. Independent contributions of hypothermia and acidosis to coagulopathy in swine. J Trauma - Inj Infect Crit Care. 2005;58:1002-10.

37. Woyke S, Rauch S, Ströhle M, Gatterer H. Modulation of Hb-O2 affinity to improve hypoxemia in COVID-19 patients. Clin Nutr. 2021;40:38-9.

38. Shepherd JRA, Dominelli PB, Roy TK, Secomb TW, Hoyer JD, Oliveira JL, et al. Modelling the relationships between haemoglobin oxygen affinity and the oxygen cascade in humans. J Physiol. 2019;597:4193-202.

39. Williams DJ, Guirgis FW, Morrissey TK, Wilkerson J, Wears RL, Kalynych C, et al. End-tidal carbon dioxide and occult injury in trauma patients: ETCO2 does not rule out severe injury. Am J Emerg Med. 2016;34:2146-9.

40. McGillicuddy DC, Tang A, Cataldo L, Gusev J, Shapiro NI. Evaluation of end-tidal carbon dioxide role in predicting elevated SOFA scores and lactic acidosis. Intern Emerg Med. 2009;4:41-4.

41. Razi E, Moosavi GA, Omidi K, Saebi A, Razi A. Correlation of end-tidal carbon dioxide with arterial carbon dioxide in mechanically ventilated patients. Arch Trauma Res. 2012;1:58-62.

42. Belenkiy S, Ivey KM, Batchinsky Al, Langer T, Necsoiu C, Baker W, et al. Noninvasive carbon dioxide monitoring in a porcine model of acute lung injury due to smoke inhalation and burns. Shock. 2013;39:495-500.

43. Pronicka E. Hypocapnic hypothesis of Leigh disease. Med Hypotheses. 2017;101:23-7.

44. Cortes-Puentes GA, Westerly B, Schiavo D, Wang S, Stroetz R, Walters B, et al. Hypercapnia alters alveolar epithelial repair by a pH-dependent and adenylate cyclase-mediated mechanism. Sci Rep. 2019;9:1-9.

45. Slottosch I, Liakopoulos O, Kuhn E, Scherner M, Deppe AC, Sabashnikov A, et al. Lactate and lactate clearance as valuable tool to evaluate ECMO therapy in cardiogenic shock. J Crit Care. 2017;42:3541.

46. Feher J. Acid-Base Physiology I: The bicarbonate buffer system and respiratory compensation. Quant Hum Physiol. Elsevier; 2012. p. 595-601.

47. Zager E, Fletcher DJ, Goggs R. Evaluation of the association between strong ion acid-base disturbances and mortality in dogs: A retrospective study. Vet Med Sci. 2018;4:206-17.

48. Choi YJ, Kim MC, Lim YJ, Yoon SZ, Yoon SM, Yoon HR. Propofol infusion associated metabolic acidosis in patients undergoing neurosurgical anesthesia: A retrospective study. J Korean Neurosurg Soc. 2014;56:135-40. 
49. Taghizadieh A, Pouraghaei M, Moharamzadeh P, Ala A, Rahmani F, Basiri Sofiani K. Comparison of end-tidal carbon dioxide and arterial blood bicarbonate levels in patients with metabolic acidosis referred to emergencymedicine. J Cardiovasc Thorac Res. 2016;8:98-101.

50. Kang TM, Nazario M, Edouard B. Propofol infusion syndrome in critically ill patients. Ann Pharmacother. 2002;36:1453-6.

51. Liu L, Liu H, Yang Y, Huang Y, Liu S, Beck J, et al. Neuroventilatory efficiency and extubation readiness in critically ill patients. Crit Care. 2012;16:R143.

52. Li J, Scott JB, Duan J, Liu K, Fink JB. More than just a screen to liberate from mechanical ventilation: treat to keep extubated? Ann Transl Med. 2019;7:S338-S338.

53. Cohen J, Shapiro M, Grozovski E, Fox B, Lev S, Singer P. Prediction of extubation outcome: A randomised, controlled trial with automatic tube compensation vs. pressure support ventilation. Crit Care. 2009;13:R21.

54. Nakos G, Batistatou A, Galiatsou E, Konstanti E, Koulouras V, Kanavaros P, et al. Lung and "end organ" injury due to mechanical ventilation in animals: Comparison between the prone and supine positions. Crit Care. 2006;10.

55. Protti A, Cressoni M, Santini A, Langer T, Mietto C, Febres D, et al. Lung stress and strain during mechanical ventilation: Any safe threshold? Am J Respir Crit Care Med. 2011;183:1354-62.

\section{Figures}




\section{Preliminary study}

Autonomous breathing after mechanical ventilation for $1 \mathrm{~h}$.
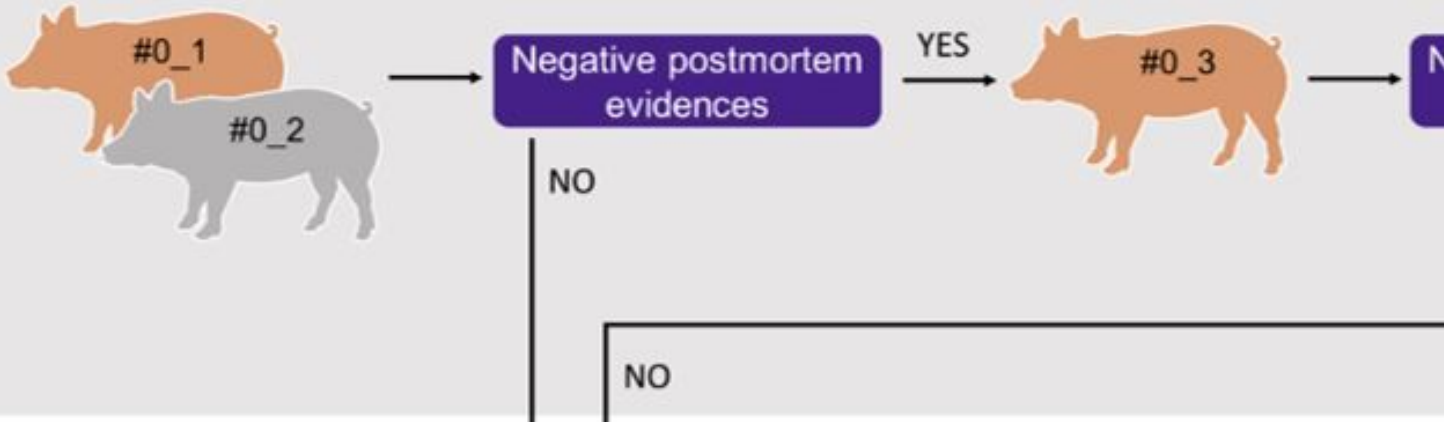
Negative postmortem evidences

\section{Pre-clinical trial}

Autonomous breathing after mechanical ventilation for $6 \mathrm{~h}$.
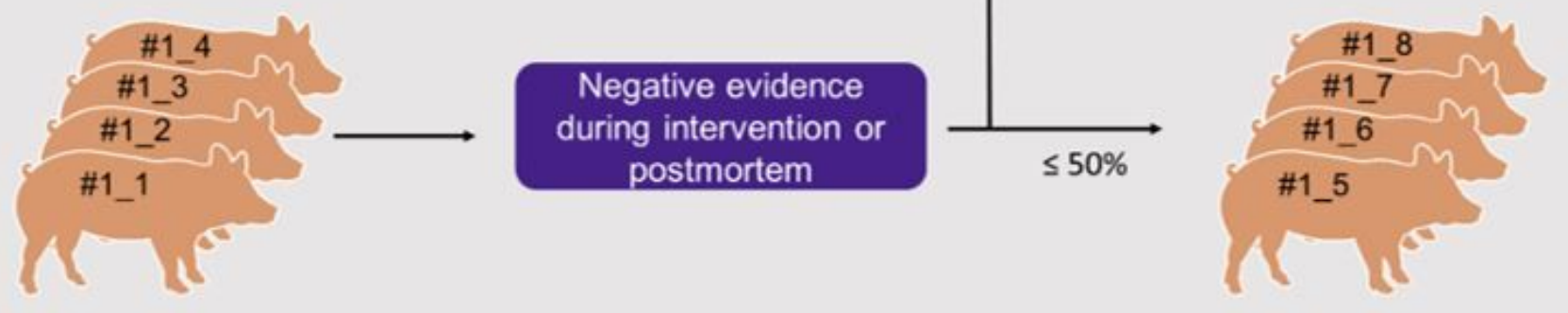

\section{Figure 1}

Experimental design of the study. 


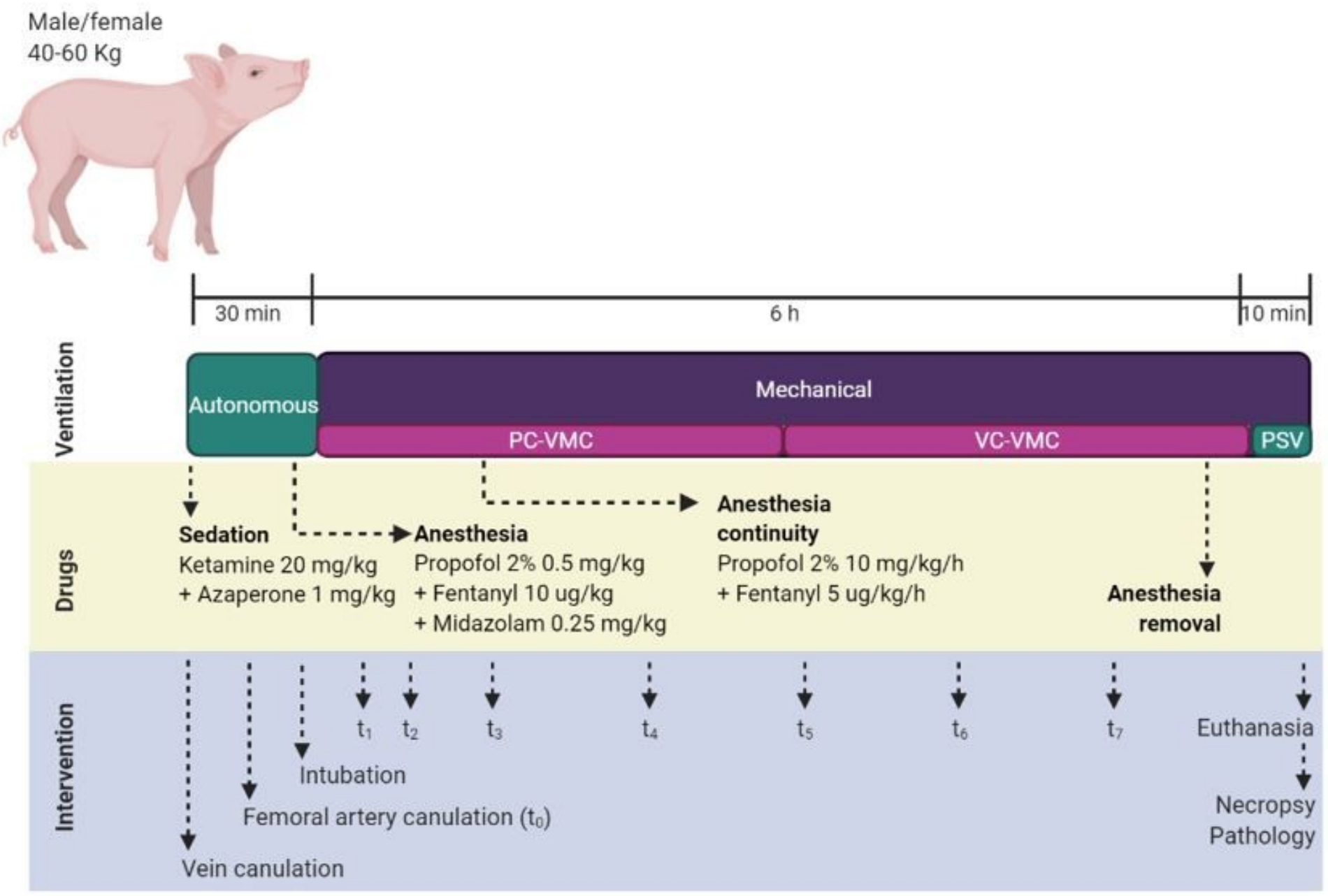

\section{Figure 2}

Timeline for experimental procedures. The diagram shows the stages carried out for drugs supplying, the interventions performed on animals for the coupling of the Masi mechanical ventilator, the sampling periods, as well as the procedures after the removal of the mechanical ventilator. PC-CMV: Pressure Control-Continuous Mandatory Ventilation, VC-CMV: Volume Control-Continuous Mandatory Ventilation, PSV: pressure support ventilation, t0-7: blood sample collection time. 


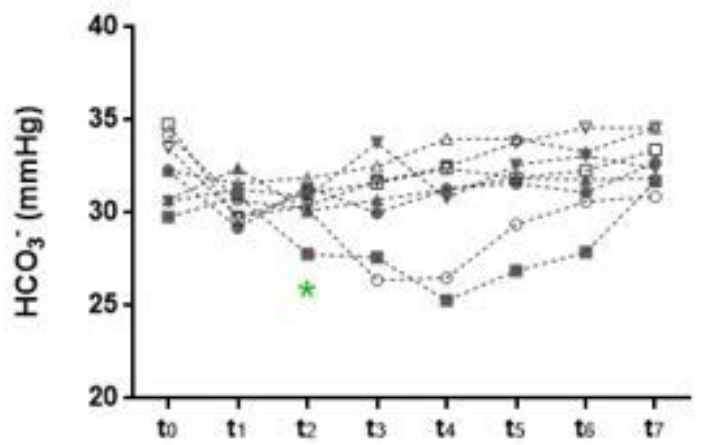

- Pig 1

- Pig 2

.4. Pig 3

-.. Pig 4

-. Pig 5

.0. Pig 6

-4. Pig 7

-.

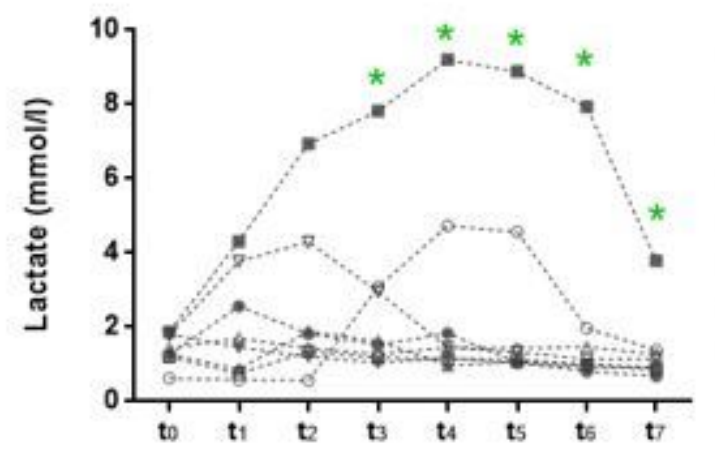

-. Pig 1

- Pig 2

-.- Pig 3

-... Pig 4

.6. Pig 5

๑. Pig 6

.s. Pig 7

-8. Pig 8
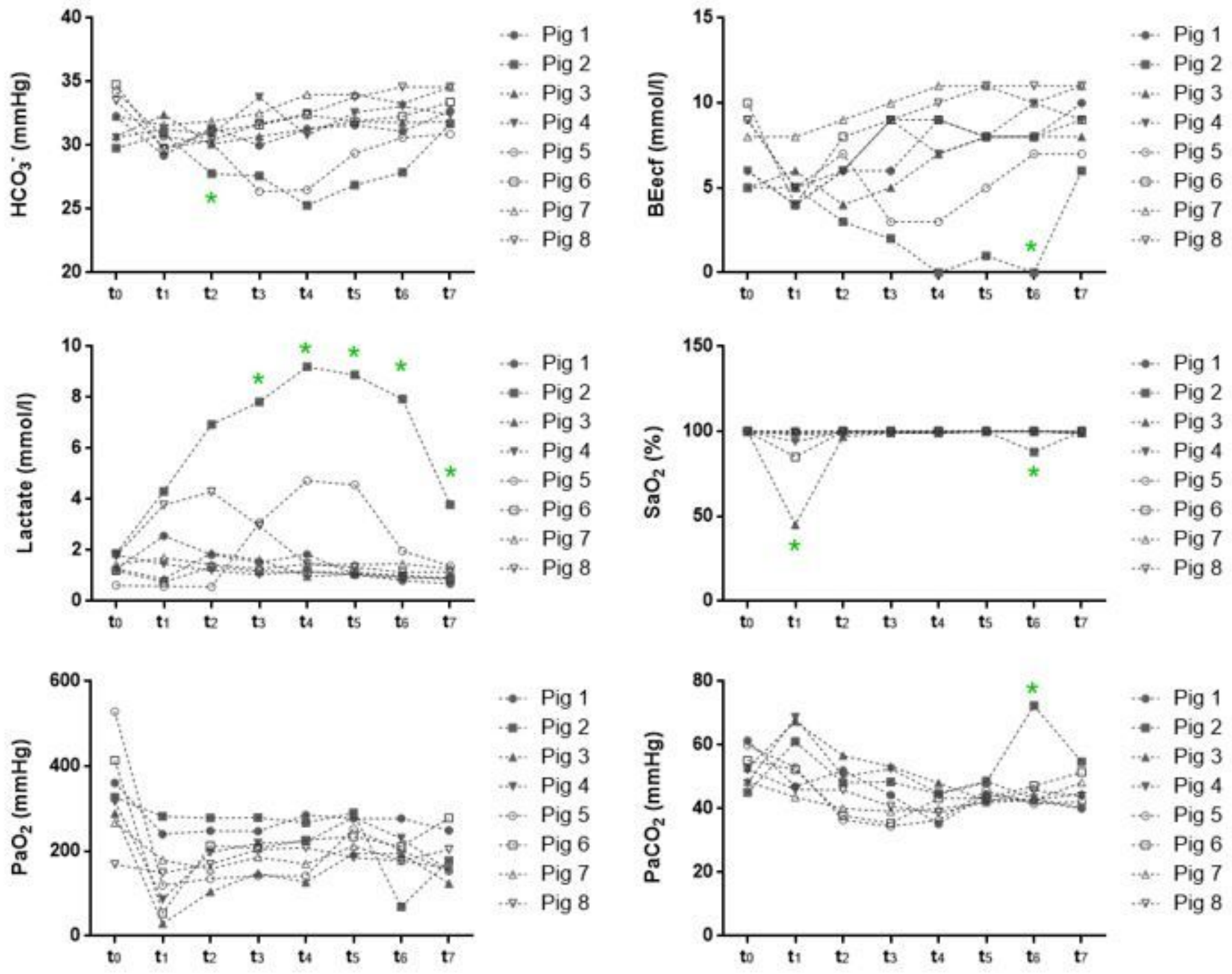

- Pig 1

- Pig 2

4.- Pig 3

-7. Pig 4

.6. Pig 5

- ․ Pig 6

.- Pig 7

.7. Pig 8

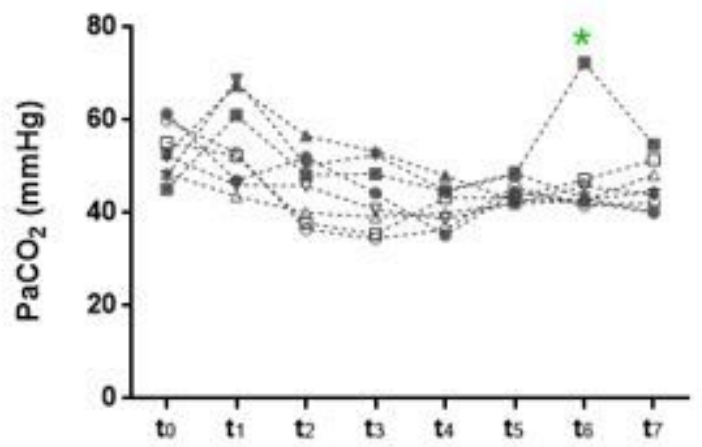

-. Pig 1

- Pig 2

-4. Pig 3

... Pig 4

-. Pig 5

c. Pig 6

.4. Pig 7

-7. Pig 8

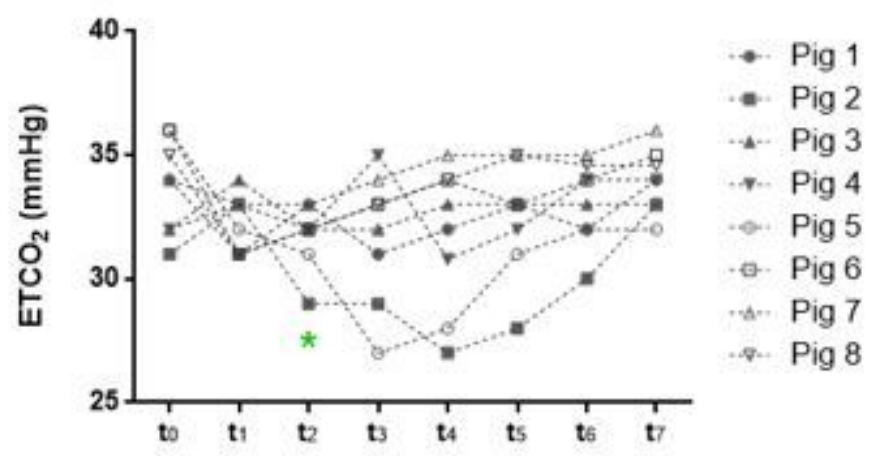

Figure 3

Effects of mechanical ventilation on arterial blood biochemical characteristics (t0-7). Blood samples from each pig were monitored over time. Biochemical parameters were registered previously ( $\mathrm{t} 0)$ and during the use of Masi mechanical ventilator (t1-7). pH: potential of hydrogen, HCO3-: bicarbonate ion, BEecf: base excess in the extracellular fluid compartment, $\mathrm{SaO2}$ : arterial oxygen saturation, $\mathrm{PaO2}$ : arterial oxygen pressure, PaCO2: arterial carbon dioxide pressure, ETCO2: end-tidal carbon dioxide, $\left.{ }^{\star}\right)$ : outliers. 

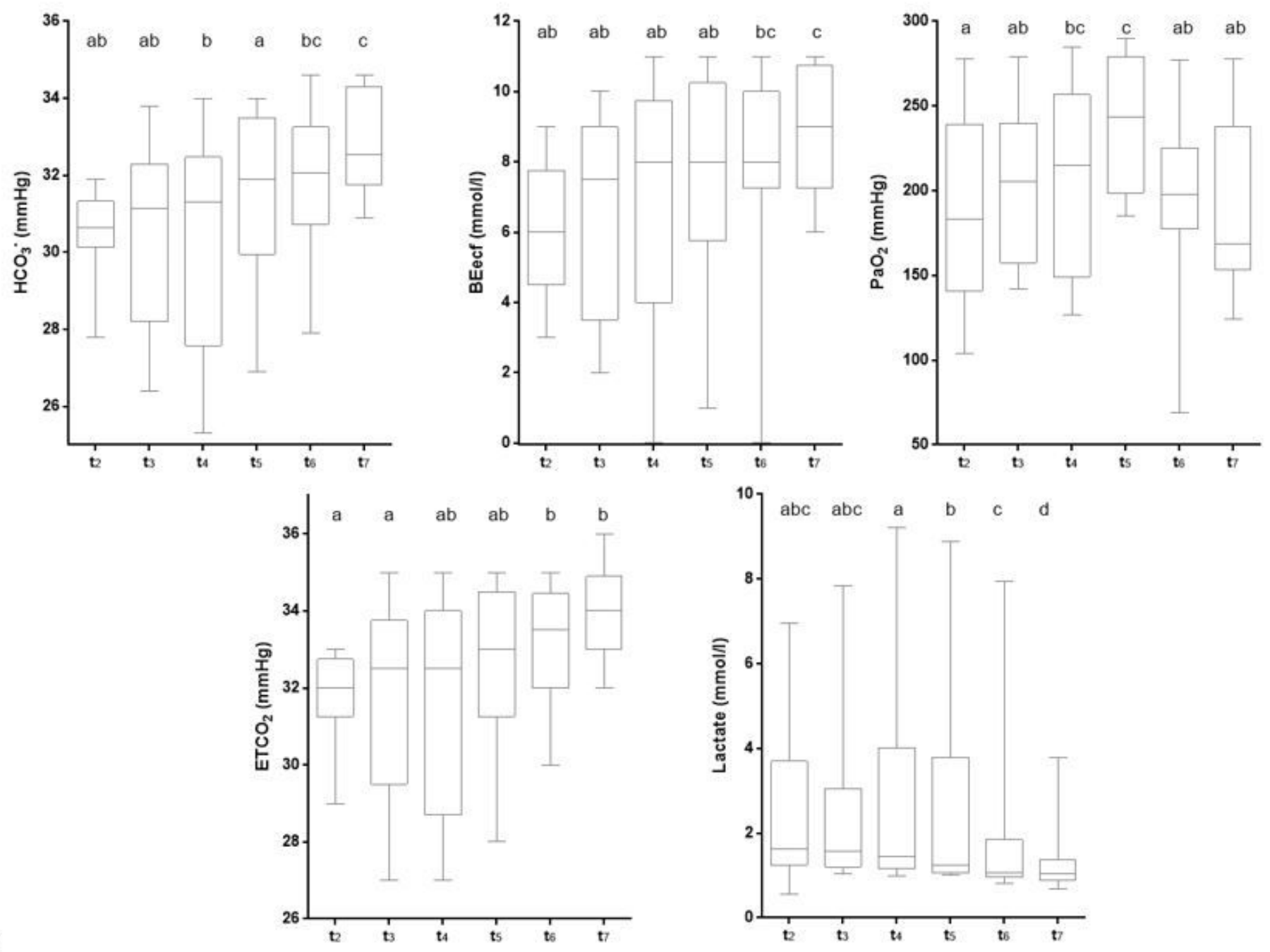

Figure 4

Box plot of some physiological parameters at t2-7 period. Median, lower and upper quartiles of bicarbonate, lactate, base excess, oxygen, and carbon dioxide arterial pressure are illustrated. Significant differences among sampling times were also represented at the top the column corresponding to each sample time with letter-based style. HCO3-: bicarbonate ion, BEecf: base excess in the extracellular fluid compartment, $\mathrm{PaO} 2$ : arterial oxygen pressure, $\mathrm{PaCO}$ : arterial carbon dioxide pressure, ETCO2: end-tidal carbon dioxide. 


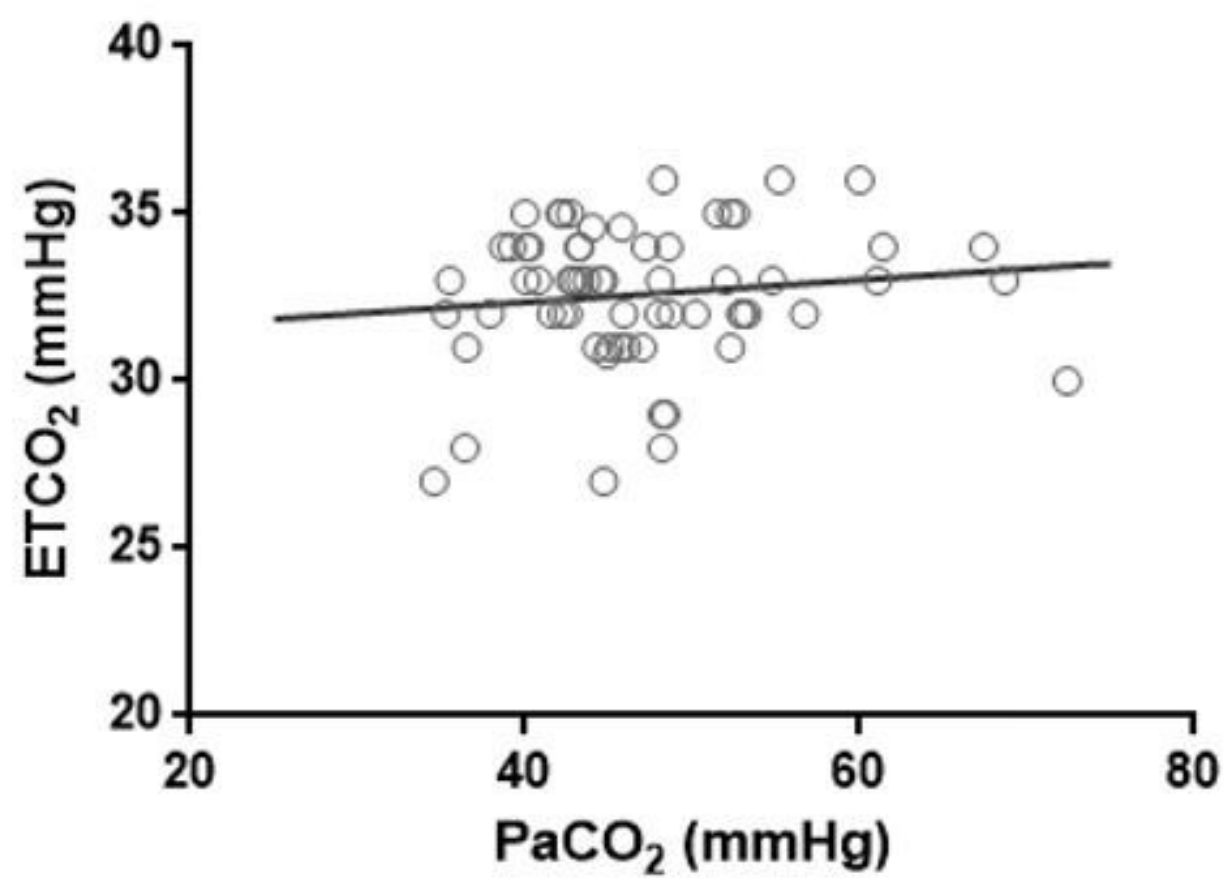

Figure 5

Scatter plot and linear regression analysis between $\mathrm{EtCO} 2$ and $\mathrm{PaCO} 2$. The solid line represents linear regression between ETCO2 and PaCO2. Spearman R-score $=0.046(p=0.718)$.

\section{Supplementary Files}

This is a list of supplementary files associated with this preprint. Click to download.

- Graphicalabstract.jpg 